\title{
Monteiro Lobato e a questão do petróleo no Brasil*
}

\author{
Monteiro Lobato and the oil question in Brazil
}

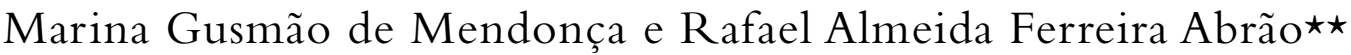

Resumo: Este trabalho procura resgatar a trajetória do empresário e escritor Monteiro Lobato, particularmente no que diz respeito às suas contribuições para o avanço da nascente indústria de petróleo no Brasil. Para tanto, a metodologia de pesquisa combinou análise documental e revisão bibliográfica, recuperando suas obras e escritos sobre o tema. A retomada de tal discussão - que envolve temas como nacionalismo em relação a recursos naturais e soberania nacional - contribui para o entendimento acerca dos conflitos permanentes entre, de um lado, os interesses de empresas estrangeiras e, de outro, os países da periferia do sistema capitalista detentores de reservas petrolíferas.

Palavras-chave: Monteiro Lobato. Petróleo. Nacionalismo. Soberania Nacional.

\begin{abstract}
This article aims to analyze the trajectory of the businessman and famous writer Monteiro Lobato. We review his contributions to the advance of the budding oil industry in Brazil. To this end, the research methodology combined document analysis and bibliographic review, recovering his works and writings on the subject. This discussion - which involves topics such as resource nationalism and national sovereignty - contributes to the understanding of the permanent conflict between, on the one hand, the interests of foreign companies and their respective home countries, and on the other, the countries on the periphery of the capitalist system that hold oil reserves.
\end{abstract}

Keywords: Monteiro Lobato. Oil politics. Nationalism. National Sovereignty.

JEL: Q4

\footnotetext{
^ Submissão: 23/10/2020 | Aprovação: 16/02/2021 | DOI: 10.29182/hehe.v24i2.778

$\star \star$ Respectivamente: (1) Doutora em História Econômica pela Universidade de São Paulo (USP). Professora Adjunta do Departamento de Relações Internacionais da Universidade Federal de São Paulo (UNIFESP) | E-mail:marinamendonca@uol.com.br | ORCID:0000-0003-3481-3838 | (2) Doutorando em Economia Política Mundial pela Universidade Federal do ABC (UFABC) | Bolsista de Doutorado pela Coordenação de Aperfeiçoamento de Pessoal de Nível Superior (CAPES) | E-mail: ra.abrao@gmail.com | ORCID: 0000-0001-9405-0719
} 


\section{Introdução}

O papel do Brasil na economia política mundial da energia tem se tornado cada vez mais relevante. Esse fato se deve especialmente às descobertas de imensas reservas de petróleo e gás na camada de pré-sal da plataforma continental brasileira a partir de 2006 . De país com escassos recursos petrolíferos, o Brasil conseguiu criar - a despeito do desinteresse inicial de grandes companhias internacionais - uma das principais empresas de energia do mundo, uma relevante indústria petrolífera local, e se transformar em um dos mais promissores produtores mundiais de petróleo e gás - com reservas, produção e exportações em consolidada ascensão, o que permitiu firmar o pré-sal como uma das mais importantes fronteiras petrolíferas no cenário energético e geopolítico global. ${ }^{1}$

Todavia, o país vive, desde 2014, um processo, liderado por setores conservadores, de desarticulação das atividades da Petróleo Brasileiro S.A., a Petrobras, sua maior empresa, e, desde 2016, a implementação de uma política voltada para a entrega de parte de suas reservas de petróleo a companhias estrangeiras, sem que haja reação popular para impedir (Azevedo, 2018; Schutte, 2019; Mendonça;Abrão, 2020). E isso se revela ainda mais desanimador se lembrarmos que a Petrobras resultou de uma grande campanha nacionalista - "O petróleo é nosso" -, desencadeada na segunda metade da década de 1940, e que se estendeu até outubro de 1953, quando foi promulgada a Lei $n^{\circ} 2004$, que criou a empresa.

Historicamente, a questão petrolífera no Brasil esteve longe de ser consensual, e foi necessária grande persistência para que o país avançasse em meio a conquistas e fracassos. Nossa trajetória em relação ao petróleo tem sido marcada pela tensão entre a atuação do Estado, a iniciativa privada e a ação das grandes companhias internacionais (Cohn, 2017).

Dessa forma, recuperar a história do petróleo no Brasil, assinalar a importância estratégica dessa commodity para a defesa e a soberania nacionais, rememorar as lutas por sua descoberta, os interesses envolvidos, a oposição que a pesquisa e a construção da empresa sofreram são de suma importância para que se possa articular um combate às políticas de desintegração da Petrobras e - quem sabe? - reverter a entrega de nossas reservas para o capital estrangeiro.

\footnotetext{
${ }^{1}$ Não se pode esquecer também que, apesar de seus recursos limitados, o Brasil foi capaz de desenvolver tecnologia de ponta no setor, com avanços principalmente em tecnologias para exploração em águas profundas e ultraprofundas (Morais, 2013).
} 
E na batalha pela descoberta de petróleo no Brasil, uma das vozes que se destacaram foi a do empresário e escritor José Bento Monteiro Lobato, cuja obra literária vem entretendo o público infantil há um século. Neste texto, procuraremos recuperar a trajetória empresarial do escritor, seu envolvimento com a extração de petróleo no Brasil, a disputa que manteve com o governo federal e, finalmente, sua prisão durante o Estado Novo (1937-1945).

Neste artigo, nosso objetivo é retomar a trajetória de Monteiro Lobato como empresário do setor petrolífero e destacar a sua relevância para o debate sobre a questão do petróleo no Brasil. Apontamos a atualidade da discussão dividida entre, de um lado, o interesse de grandes conglomerados internacionais, e, de outro, da preservação da soberania nacional. Ressalta-se a importância da retomada dos argumentos levantados por Monteiro Lobato, especialmente em um momento em que, após a descoberta das reservas do pré-sal, em 2007, o Brasil tem se transformado em um grande produtor de petróleo.

Além desta introdução, o trabalho possui outras quatro seções. Na segunda seção, apresentamos a trajetória de Lobato para se consolidar como um dos principais nomes da literatura nacional e se inserir como respeitável figura na criação da identidade nacional por meio de suas publicações. Em uma terceira parte, dedicamo-nos a compreender a conciliação entre o trabalho de escritor e a sua vida de empresário, para, em uma quarta parte, debruçarmo-nos sobre as contribuições de Monteiro Lobato para a questão do petróleo no Brasil. Por fim, na quinta seção, esboçamos nossas considerações finais, traçando um paralelo entre dois contextos históricos distintos: as discussões levantadas por Lobato e a disputa entre interesses internos e externos suscitados pela descoberta do pré-sal.

\section{O surgimento de um grande escritor}

José Bento Monteiro Lobato (1882-1948)² nasceu em Taubaté, no estado de São Paulo. Era filho de José Bento Marcondes Lobato, fazendeiro de café do Vale do Paraíba, e de Olímpia Monteiro Lobato. Seu avô materno, José Francisco Monteiro, Visconde de Tremembé, era também grande proprietário de terras.

Concluiu os cursos primário e ginasial em Taubaté, onde começou, desde cedo, a escrever para o jornal estudantil O Guarani. Em 1896, mudou-se

\footnotetext{
${ }^{2} \mathrm{Na}$ verdade, o escritor foi registrado como José Renato Monteiro Lobato, adotando, mais tarde o nome do pai (Abreu et al., 2001).
} 
para São Paulo para concluir os estudos preparatórios, e passou a escrever para os jornais O Patriota e A Pátria. Pretendia inscrever-se na Escola de Belas Artes, mas com o falecimento do pai, em 1898, foi viver com o avô materno, que não aceitou sua escolha e o convenceu a se matricular na Faculdade de Direito do Largo de São Francisco, em São Paulo.

Dessa forma, iniciou os estudos superiores em 1900, mas nunca se interessou de fato pelo curso e, na faculdade, passou a frequentar o grêmio, criando, com alguns colegas, a associação literária O Cenáculo. Fundou também o jornal O Minarete, editado em Pindamonhangaba, para o qual, muitas vezes, escrevia todas as matérias, e passou a colaborar com os periódicos Combatente, de São Paulo, e Povo, publicado em Caçapava. De acordo com Carmen Luzia de Azevedo, Márcia Camargos eVladimir Sacchetta, no início do curso de Direito, Monteiro Lobato apenas demonstrava inconformismo com o que considerava uma sociedade decadente. Mas, com o tempo, iniciou uma "profissão de fé pelos valores de justiça, liberdade e igualdade social" (Azevedo; Camargos; Saccheta, 2000, p. 9).

Formou-se em 1904 e voltou a Taubaté. Pouco depois, em 1906, foi designado procurador interino da cidade, sendo efetivado na promotoria de Areias no ano seguinte. Em 1908, casou-se com Maria Pureza Natividade, com quem teria quatro filhos. Mesmo exercendo as funções de promotor público, não abandonava as atividades literárias, escrevendo artigos para periódicos do interior e traduzindo matérias para o jornal O Estado de S. Paulo. Em 1909, passou a colaborar com A Tribuna, de Santos, e Gazeta de Notícias, do Rio de Janeiro, mas seus ganhos mal davam para sustentar a família.

Em 1911, sua vida tomou novo rumo, pois, com a morte do avô, herdou a fazenda Buquira, em Taubaté. Mudou-se para lá e procurou modernizar a propriedade, introduzindo novos métodos de produção e administração. Não teve sucesso e, no final de 1914, publicou artigo no jornal O Estado de S. Paulo, com o título de "Uma velha praga", em que descrevia suas agruras na administração da fazenda e os problemas provocados pelos caboclos, entre eles, o das queimadas, que levavam ao desgaste das terras. Segundo ele,

[...] se lá fora o fogo da guerra lavra implacável, fogo não menos destruidor devasta nossas matas [...]. A serra da Mantiqueira ardeu como ardem aldeias na Europa, e é hoje um cinzeiro imenso, entremeado aqui e acolá de manchas de verdura [...]. Tudo mais é crepe negro. [...] É peculiar de agosto, e típica, esta desastrosa queima de matas; nunca, porém, assumiu tamanha violência, nem alcançou tal extensão [...]. Qual a causa da renitente calamidade? 
[...] A nossa montanha é vítima de um parasita, um piolho da terra, peculiar ao solo brasileiro [...]. Este funesto parasita é o CABOCLO, espécie de homem baldio, semi-nômade, inadaptável à civilização, mas que vive à beira dela na penumbra das zonas fronteiriças. À medida que o progresso vem chegando com a via férrea [...]. Encoscorado numa rotina de pedra, recua para não adaptar-se. (Monteiro Lobato, 1951d, p. 233-235)

Contudo, os autores Carmen Lucia Azevedo, Marcia Camargos e Vladimir Sacchetta advertem que,

Por trás das críticas de Lobato a esse procedimento danoso, estão muito mais que os interesses de um fazendeiro lesado. Suas teses também denunciam a incapacidade do governo e da grande propriedade agrícola em adotar uma postura mais moderna e economicamente consequente, ou seja, um desenvolvimento que não se fizesse à custa de deixar um rastro de áreas decaídas como acontecera com o próprio Vale do Paraíba. (Azevedo; Camargos; Saccheta, 2000, p. 31)

Diante do sucesso da matéria, publicou outra, intitulada "O caboclo e o urupê do pau podre que vegeta no sombrio da mata" (1914), origem de seu famoso personagem Jeca Tatu, ${ }^{3}$ marcado pela preguiça e pela ignorância, características que criavam empecilhos para a modernização da agricultura.

É preciso assinalar que, embora criticasse acidamente a população rural brasileira, isso não significava uma postura antinacionalista, pelo contrário. Tanto que, em artigo publicado no final de 1916, na Revista do Brasil, atacava duramente a falta de apego à nossa cultura, "denunciando o imitativismo que impregna a mentalidade brasileira, contente em reproduzir, em todos os níveis, o modelo europeu" (Azevedo; Camargos; Saccheta, 2000, p. 36).

Em 1917, o fracasso como fazendeiro o fez vender a propriedade e a se mudar para a capital, onde escrevia para várias publicações, entre as quais O Estado de S. Paulo e Revista do Brasil, esta fundada no ano anterior. E, a partir de 1918, suas atividades se tornariam ainda mais intensas: primeiramente, comprou a Revista do Brasil, adotando uma linha editorial marcadamente nacionalista. Fundou também uma editora, na qual publicou seu primeiro livro, Urupês (1918), uma coletânea de artigos e contos já editados. O personagem Jeca Tatu se tornaria, então, alvo de intensos debates, e a advertência

\footnotetext{
${ }^{3}$ O personagem foi criado pelo escritor em 1914, no artigo "Urupês", publicado no jornal O Estado de S. Paulo. Jeca Tatu era originário do Vale do Paraíba e, com característica caipira, se consolidaria como uma caricatura dos habitantes de áreas pobres e rurais do país no imaginário popular (Schwarcz; Starling, 2015).
} 
de médicos sobre as condições sanitárias no interior do Brasil o levou a refletir sobre o tema e a apontar para o fato de que, na verdade, a população rural tinha grande resistência física, e que as diversas moléstias de que era vítima justificavam sua indolência. A partir daí, passou a publicar artigos nos quais defendia a adoção de políticas de saneamento básico no país inteiro, os quais foram reunidos no livro Problema vital, publicado pela Sociedade Eugênica de São Paulo e pela Liga Pró-Saneamento do Brasil.

Com a renda obtida pelos dois livros - Urupês e Problema vital-, fundou, também em 1918, a Companhia Gráfico-Editora Monteiro Lobato, que passou a publicar obras de autores conhecidos, como Menotti del Picchia, Oswald de Andrade e Ribeiro Couto, e logo se tornaria a mais bem-sucedida empresa do ramo no país. Suas atividades empresariais acabaram por tirar-lhe o tempo necessário para escrever.Assim, em 1919, publicou apenas coletâneas de seus antigos artigos, que foram reunidos nos livros Cidades mortas, Ideias de Jeca Tatu e Onda verde.

\section{A vida de escritor e empresário}

A criação da editora passou a tomar grande tempo de Monteiro Lobato. Apesar disso, em 1921, ele conseguiu se dedicar a narrativas infantis, divulgando A menina do narizinho arrebitado (1921), que chegou a vender 50 mil exemplares, e O Saci (1921). No ano seguinte publicou O Marquês de Rabicó (1922), Fábulas (1922) e Jeca Tatuzinho (1924). Assinale-se que, neste último, voltava a preconizar a necessidade de saneamento básico como instrumento para combater os males que afligiam a população rural. $\mathrm{O}$ sucesso da obra entusiasmou o Laboratório Fontoura, e Monteiro Lobato adaptou o livro para ser utilizado como peça de propaganda da empresa.

Embora publicasse obras de autores renomados, como Oswald de Andrade, um dos principais promotores da Semana de Arte Moderna de 1922, Monteiro Lobato fez duras críticas ao evento, por considerá-lo manifestação de "estrangeirismo". ${ }^{4}$ E, no ano seguinte, continuou a colher sucessos para

\footnotetext{
${ }^{4}$ De acordo com Alfredo Bosi, a crítica de Monteiro Lobato à Semana de Arte Moderna se deve ao fato de que ele foi, antes de tudo, "um intelectual participante que empunhou a bandeira do progresso social e mental de nossa gente. [...] depois de Euclides da Cunha e de Lima Barreto, ninguém melhor do que ele soube apontar as mazelas físicas, sociais e mentais do Brasil oligárquico e da I República, que se arrastava por trás de uma fachada acadêmica e parnasiana. Nessa perspectiva, Lobato encarnou o divulgador agressivo da Ciência, do progressismo, do 'mundo moderno', tendo sido um demolidor de tabus, à maneira dos socialistas fabianos, com um superávit de verve e sarcasmo.” (Bosi, 1970, p. 242).
} 
sua editora e para sua carreira de escritor, publicando $O$ macaco que se fez homem (1923) e O mundo da lua (1923).

Porém, a revolução de 1924, que transformou São Paulo num teatro de guerra durante o mês de julho daquele ano, acabou por levar à paralisação da economia da cidade, o que, evidentemente, afetou gravemente sua editora e levou à prisão de um de seus sócios e presidente da empresa, José Carlos de Macedo Soares. Como reação, em agosto de 1924, Monteiro Lobato enviou uma carta a Arthur Bernardes, presidente da República, em que criticava acidamente seu governo e exigia uma reforma eleitoral. E embora no ano seguinte tenha tentado recuperar a empresa mediante o lançamento de novos autores voltados para o público infantil e a publicação de antigas traduções de obras conhecidas, a política econômica do governo Arthur Bernardes e a adoção de novas diretrizes para o Banco do Brasil acabaram por levar a editora à falência (Azevedo; Camargos; Sachetta, 2000).

Mas Monteiro Lobato resistia e, juntamente com alguns sócios, fundou, no mesmo ano, a Companhia Editora Nacional. A seguir, mudou-se para o Rio de Janeiro, onde passou a escrever séries de artigos para os periódicos $O$ Jornal e $A$ Manhã.Tentou também uma vaga na Academia Brasileira de Letras $(\mathrm{ABL})$, mas foi derrotado.

Em 1927, com a posse de Washington Luiz na Presidência da República, foi nomeado adido comercial do Brasil em Nova York, para onde se mudou. A pujança da cidade e o grande crescimento da economia norte-americana o entusiasmaram sobremaneira, e ele começou a cogitar de meios para conseguir que o Brasil copiasse o exemplo dos Estados Unidos. Para ele, o fator decisivo para que aquele país alcançasse tal desenvolvimento era a ênfase dada às indústrias do ferro e do petróleo. Ressalte-se que, no caso do petróleo, a indústria mundial já estava, na época, bastante avançada, inclusive em países vizinhos ao Brasil, como Argentina e Venezuela, e o setor já apresentava altos níveis de concentração, resultados da atuação de empresas estadunidenses como a Standard Oil of New Jersey e a Gulf Oil, além da britânica Anglo-Persian e a anglo-holandesa Royal-Dutch Shell (Yergin, 1991).

Por outro lado, e mesmo antes de ir viver nos Estados Unidos, Monteiro Lobato já manifestava entusiasmo com o país, e considerava Henry Ford o modelo ideal de empresário, tanto que, em 1926, escrevera uma série de artigos para O Jornal, louvando o ideário fordista. E, no ano seguinte, traduziu e publicou dois livros de autoria de Ford: Minha vida e minha obra (1927) e 
Hoje e amanhã (1927), ambos pela Companhia Editora Nacional. Sobre o empresário, assim se manifestava Monteiro Lobato:

Postas nas bases de Henry Ford a indústria deixa de ser o Moloch ${ }^{5}$ devorador de milhões de criaturas em benefício dum núcleo de nababos e transforma-se em cornucópia inextinguível de bens. [...] Extingue-se o sinistro antagonismo entre o capital e o trabalho, que ameaça subverter o mundo. Reajusta-se a produção ao consumo e graças à distribuição equitativa desaparece o monstruoso cancro da miséria humana. (Monteiro Lobato apud Azevedo; Camargos; Sacchetta, 2000, p. 106)

Conforme apontaram os autores Carmen Lucia de Azevedo, Marcia Camargos e Vladimir Sacchetta:

O modelo sonhado por Monteiro Lobato - e que, a seu ver, as iniciativas de Henry Ford tão brilhantemente personificavam inseria-se em um tipo de capitalismo onde os conceitos marxistas clássicos de mais-valia e luta de classes estavam fora de cogitação. [...] Neste paradigma, o fim visado não é o lucro, mas o bem comum; não é a exploração, mas a felicidade do operário; não é enganar o consumidor, mas melhorar o nível de vida da coletividade. Não é, enfim, a acumulação financeira a qualquer preço, mas a resolução das mazelas que afligem o planeta. (Azevedo; Camargos; Sacchetta, 2000, p. 106)

Lobato interessou-se também por siderurgia. Depois de entrar em contato com William H. Smith, engenheiro e ex-diretor da Ford, que desenvolvera um novo tipo de alto-forno, considerado por Lobato extremamente adequado às condições brasileiras, passou a ser ferrenho defensor do desenvolvimento siderúrgico no Brasil, tanto que, em 1927 escrevera ao amigo Godofredo Rangel:

Meu plano agora é um só: dar ferro e petróleo ao Brasil. Estou em carteação com Mr.W. H. Smith, de Detroit, sobre um novo processo siderúrgico, perfeitamente fit às condições carbônicas do Brasil. Terei de ir lá estudar o processo e então visitarei a Ford e o Ford. (Monteiro Lobato, 1951b, p. 302)

O entusiasmo de Monteiro Lobato com os Estados Unidos e a cultura norte-americana era de tal ordem que ele determinou a venda de todas as suas ações da Companhia Editora Nacional para investir na Bolsa de Nova

\footnotetext{
${ }^{5}$ Para o povo do Reino de Amon, na Palestina, era Deus. Para alguns cristãos e para a cabala, era o demônio.
} 
York, que vivia naqueles anos um período de grande euforia. Mas a alegria durou pouco, e em outubro de 1929, com a quebra da Bolsa, perdeu todos os seus investimentos. Assim ele descreveu o episódio:

E afinal a crise veio. [...] A 23 de outubro desse funesto ano de 1929 o arranha-céu especulativo da bolsa, que vinha desde a guerra a erguer-se num ímpeto jamais observado, desabou. A baixa nesse dia foi ultra-violenta e indicativa não das oscilações comuns dos tempos normais, mas de terremoto em perspectiva, de tromba d'água trazida nas asas de um ciclone. Pânico... (Monteiro Lobato, 1951a, p. 265)

Mesmo tendo perdido tudo, escreveu o livro América, no qual narrava suas impressões sobre os Estados Unidos, e continuou a elogiar o país e sua cultura:"[...] é impossível dar uma ideia do que é a especulação de títulos na América. Nisso, como em quase tudo mais, esta nação se mostra sui generis, única, impossível de medir-se por meio dos velhos estalões comuns à velha humanidade" (Monteiro Lobato, 1951a, p. 270-271). A seguir, voltou a se dedicar à literatura infantil.

\section{O negócio do petróleo}

Logo depois da vitória da Revolução de 1930, o governo provisório demitiu diversos funcionários de representações diplomáticas no exterior, e Monteiro Lobato teve de deixar o cargo. Antes de voltar ao Brasil, em 1931, escreveu uma longa carta a Getúlio Vargas, apontando aqueles que, segundo ele, eram os principais problemas do país: o ferro, o petróleo e o trigo. $\mathrm{Na}$ missiva, afirmava: "A primeira significação do ferro é transporte, transporte significa mobilização de reservas naturais; mobilização de reservas naturais significa desenvolvimento econômico ou riqueza" (Monteiro Lobato apud Azevedo; Camargos; Sacchetta, 2000, p. 125).

Note-se que Lobato tinha uma compreensão prévia da relevância do petróleo para o desenvolvimento econômico e de sua relação com a questão da soberania nacional, com base em reflexões obtidas a partir da Primeira Guerra Mundial, quando o hidrocarboneto foi utilizado em armas de guerra e no transporte (Morais, 2013). A partir de então, o valor estratégico e militar do petróleo se tornou incontestável. ${ }^{6}$

\footnotetext{
${ }^{6}$ Posteriormente, outros acontecimentos históricos tornariam o fator estratégico e militar ainda mais evidente, especialmente como se viu a partir da busca por reservatórios durante a Segunda Guerra Mundial
} 
Portanto, mesmo numa época em que as reflexões sobre a centralidade do petróleo ainda começavam a aparecer, o pensamento do escritor sobre o seu papel se aproximava do que mais tarde seria debatido por pesquisadores dedicados à geopolítica da energia. É o caso, por exemplo, de Fuser (2013), para quem o petróleo se tornou um requisito fundamental para a sobrevivência, segurança e garantia de bem-estar de todos os Estados. Já Amineh e Guang (2014) classificam a energia como um elemento fundamental da economia mundial e uma condição básica para a mobilização de outros recursos da economia.

Ao retornar ao país, Lobato instalou-se em São Paulo, de onde tentou convencer o novo governo a apoiar suas ideias sobre a necessidade de dedicar esforços para superar os problemas siderúrgico e petrolífero. Dessa forma, escreveu novamente a Getúlio Vargas, informando que havia mantido tratativas com representantes soviéticos e que estes manifestaram interesse em trocar petróleo refinado por café, cacau, borracha e couro (Azevedo; Camargos; Sachetta, 2000, p. 126).

O presidente e seus assessores não lhe deram a menor atenção. Monteiro Lobato, então, procurou apoio de empresários brasileiros e fundou, no mesmo ano, o Sindicato Nacional de Indústria e Comércio, dedicado à exploração de ferro, e a Companhia Petróleos do Brasil (Azevedo, Camargos, Sachetta, 2000). Mas nunca se conformou com a falta de resposta do governo, tanto que, em 1935, publicaria no Diário de S. Paulo artigo intitulado "Os grandes crimes contra os povos", em que denunciava a política de queima de estoques de café adotada a partir de 1931:

A economia humana é em linhas gerais muito simples: uns produzem - outros transportam e lidam com os produtos - todos consomem. E o ideal é que todos possam consumir e a produção nunca seja maior nem menor que o consumo. Mas na Ordem Social vigente o jogo financeiro na passagem do produto das mãos do produtor para as do consumidor faz que apesar da superprodução milhões de criaturas humanas vivam no regime do subconsumo e até morram de fome. E de tal modo a pulsação econômica do mundo se foi perturbando com a hipertrofia do jogo financeiro, que chegamos ao absurdo impasse duma ordem social que só pode subsistir por meio da destruição cada vez maior de vidas em guerras mundiais periódicas e da destruição igualmente monstruosa de produtos de alimentação na paz. Do impasse veio o dilema: ou o

pela Alemanha, na região do Cáucaso, e pelo Japão, na Indonésia, além da centralidade que a predominância petrolífera dos Estados Unidos teve para o resultado do conflito (Yergin, 1991). 
mundo destrói essa forma cancerosa de capitalismo, como fez a Rússia, ou essa forma de capitalismo destrói a humanidade. Que capitalismo? $\mathrm{O}$ anônimo internacional controlador dos governos fracos e o verdadeiro promotor das guerras entre os governos fortes. [...] Quem examina a contribuição do Brasil para o status quo dessa monstruosa economia assombra-se. Para ela o Brasil contribuiu de duas maneiras: uma passiva, não explorando as suas riquezas do subsolo; e outra ativa, queimando imensas massas de produtos de seu solo. Hoje trataremos apenas da queima de 80 milhões de sacas de café realizada de 1931 para cá. (Monteiro Lobato, s. d., p. 118)

A seguir, defendia a proposta soviética de troca de petróleo por café, cacau, borracha e couro e, denunciando a participação do governo numa suposta conspiração internacional, deixava transparecer seu ressentimento por não ser levado a sério:

Pergunto: por que motivo o nosso governo recusou o mais maravilhoso negócio que jamais apareceu para o café - uma solução que não só acabava com a superprodução como eventualmente poderia dar ao nosso café um freguês tão grande ou maior que os Estados Unidos? E um negócio que além disso nos resolvia o problema da gasolina, do querosene, do óleo combustível e do óleo lubrificante, fazendo-nos economizar os milhões e milhões de dólares gastos todos os anos na compra desses produtos? Por que não foi dada nem sequer uma simples resposta de cortesia, um simples não, a quem apresentou a proposta russa? A solução do enigma é uma só: o nosso governo não tem coragem de antepor o bem público, as verdadeiras necessidades do país, a felicidade e a prosperidade de 45 milhões de pobres diabos coloniais que somos, aos interesses dos grupos financeiros daqui, ligados ao Capitalismo Anônimo Internacional, que paira sobre o mundo como tremendo Pássaro $\mathrm{Roca}^{7}$ controlador dos governos fracos e promotor de guerras entre os governos fortes. Tanto dentro da forma democrática como dentro de qualquer forma de ditadura, os governos dos países fracos não passam de bonecos nas mãos do Poder Oculto do Capitalismo Internacional Anônimo - do qual até agora só um país se salvou: a Rússia. (Monteiro Lobato, s. d., p. 123)

Evidentemente, não se poderia esperar que Monteiro Lobato tivesse conhecimento profundo de teoria econômica, e que, portanto, compreendesse a lógica intrínseca à política de defesa do café, mantida pelo governo revolu-

\footnotetext{
${ }^{7}$ Ave fictícia, cuja origem está nos contos de As mil e uma noites.
} 
cionário. ${ }^{8}$ Também não se poderia exigir que dominasse perfeitamente a História Econômica, de tal modo a entender a natureza e a evolução do capitalismo. Porém, mesmo com um conhecimento superficial, ele parecia não perceber que a Revolução Russa tinha como objetivo fundamental implantar o socialismo, e que o Estado tivera um papel fundamental no desenvolvimento do capitalismo nos Estados Unidos. O que o movia se assemelhava a um misto de liberalismo, individualismo, voluntarismo e paternalismo, e bastaria a qualquer governo a disposição de enfrentar aquilo que chamava de "Capitalismo Anônimo Internacional".

Segundo seu raciocínio, esse "Capitalismo Anônimo Internacional" parecia pairar sobre tudo e todos, dominando os governos fracos por meio de um "poder oculto". Assim, bastaria a existência de um governo forte para que as medidas necessárias ao enfrentamento dessa entidade fossem tomadas. A partir de então, todos os problemas estariam resolvidos. Aos empresários com espírito empreendedor e com correta visão dos interesses da nação estaria reservado um futuro de pleno sucesso em seus negócios, e a pátria se libertaria de todos os seus males. Ao Estado caberia apenas apoiar o empresariado e esperar pelo momento em que o país se tornasse tão grande quanto os Estados Unidos. Em suma, era uma visão quase mítica do papel do governo e do Estado, tirada de uma impressão idílica dos Estados Unidos. A crise, assim, seria obra deste "poder oculto". Quanto à depressão econômica que se seguiu ao colapso da Bolsa de Nova York e à inação do governo de Herbert Hoover para enfrentar as consequências, simplesmente não eram consideradas.

À parte a superficialidade de suas análises, o fato é que Monteiro Lobato não aceitava o fato de seus projetos e ideias não serem levados a sério pelas autoridades governamentais. Dessa forma, por meio de diversos artigos na imprensa, passou a atacar o contrato assinado entre o governo brasileiro e a empresa Itabira Iron Ore Company que, segundo ele, utilizaria métodos atrasados na industrialização do ferro. Em seguida, reuniu esses trabalhos num livro intitulado Ferro, publicado em 1931, no qual chegava a dizer que:

Indispensável nos compenetrarmos, de uma vez para sempre, da grande verdade: - nosso problema não é político nem racial nem climatérico, mas pura e simplesmente econômico. [...]. Os males sem conta que nos afligem decorrem todos da mesma fonte, a pobreza - e só a riqueza os curará. [...] Só temos um problema - o

\footnotetext{
${ }^{8}$ A respeito da política de defesa do café após1930, ver especialmente o capítulo 30 de Furtado (1969).
} 
econômico. Só temos um caminho para a cura do proteico mal nacional - a riqueza. Assegurada esta, tudo mais se resolva automaticamente. (Monteiro Lobato, s. d., p. 128-129)

De todo modo, Lobato manteve seu entusiasmo com a perspectiva de exploração de ferro e petróleo, certo de que estes seriam a base para que o Brasil se tornasse um país rico. E no final de 1931, lançou ações da Companhia Petróleos do Brasil, que foram rapidamente vendidas. O sucesso da empreitada o estimulou a criar, ao lado do empresário Edson de Carvalho, outro crítico do governo, a Companhia Petróleo Nacional, em 1932, com o objetivo de explorar petróleo em Alagoas, onde - acreditava - localizava-se "o ponto talvez no mundo onde existia em maiores quantidades e melhor condição estratégica para a exportação" (Monteiro Lobato apud Azevedo; Camargos; Sacchetta, 2000, p. 150).

Diante da eclosão da chamada Revolução Constitucionalista, em 1932, Monteiro Lobato decidiu se manter neutro, pois considerava muito mais importante concentrar sua atenção na questão do ferro e do petróleo, criando, para isso, outras empresas. E, como ainda permanecia com dificuldades econômicas, voltou a fazer traduções e a se dedicar aos livros infantis, publicando, Viagem ao céu (1932), História do mundo para crianças (1933) e As caçadas de Pedrinho (1933).

Mas não desistiu de suas empresas, e em maio de 1934, por meio de uma delas - Companhia de Petróleo do Brasil -, emitiu ações com o objetivo de obter recursos para a continuidade da perfuração de um poço em Araquá, município de Piracicaba, no estado de São Paulo. No entanto, na mesma ocasião, o Departamento Nacional de Produção Mineral (DNPM) divulgou estudo que atestava a inexistência de petróleo naquela região.

A reação de Monteiro Lobato foi imediata, acusando o DNPM de falsificação de laudos geológicos com a finalidade de boicotar pesquisas realizadas por empresas nacionais, pois, segundo ele, o órgão estaria, na verdade, defendendo interesses de grandes conglomerados estrangeiros, notadamente a Standard Oil, que pretendiam manter os recursos brasileiros inexplorados para o caso de eventuais perspectivas de lucros futuros.

Note-se que a solução defendida por Lobato era nacionalista, mas não passava pela restrição ao capital estrangeiro, tampouco pela exploração monopolista do Estado. $\mathrm{Na}$ verdade, ele defendia a liberação da exploração no Brasil a todos os interessados, sem diferenciação da nacionalidade do capital. 
O que Lobato não admitia era que o Estado não conseguisse extrair petróleo e ainda dificultasse a atuação da iniciativa privada, impossibilitando que um país com as dimensões do Brasil desenvolvesse uma indústria petrolífera, que já oferecera enormes benefícios, particularmente para a economia dos Estados Unidos, cuja experiência inspirava suas ideias (Cohn, 2017).

Em julho de 1934, quando foi aprovado o Código de Minas (Brasil, 1934), Monteiro Lobato se viu novamente prejudicado, tendo em vista que aquele diploma legal estabelecia novos critérios para exploração de jazidas minerais, subordinando as atividades das empresas privadas ao DNPM. Imediatamente, ele passou a acusar o governo de defender, por meio da nova legislação, os interesses externos. E foi na crítica às companhias internacionais que os argumentos de Monteiro Lobato ganharam destaque, pois atacavam o documento intitulado "Bases para o inquérito sobre o petróleo", elaborado pelo Ministro da Agricultura, Odilon Braga, e por técnicos do DNPM (Braga, 1936).

Nesse documento eram relatados os esforços do Serviço Geológico e Mineralógico do Brasil, órgão que antecedera o DNPM, entre 1919 e 1933, as qualificações do corpo de técnicos membros do Ministério da Agricultura e, contrapondo-se aos repetidos argumentos de Lobato, deixava-se claro que não bastava haver petróleo em países vizinhos ou mesmo que a extensão territorial do país tivesse dimensões continentais para comprovar a existência de jazidas no Brasil (Dias; Quaglino, 1993).

No entanto, Lobato insistia em atacar a legislação vigente, a ineficiência do DNPM e a submissão aos trustes internacionais, acusando o governo de inação e de estar a serviço de interesses estrangeiros. Afirmava que aos grupos internacionais interessava aplicar uma política para travar a exploração, com o objetivo de manter o Brasil como importador, considerando-se a situação de superprodução mundial do insumo. Quanto à legislação, criticava particularmente o Código de Minas, por desestimular a investigação do subsolo e o ingresso da iniciativa privada no setor (Cohn,2017), e a atuação do DNPM, pela contratação de técnicos supostamente ligados aos trustes internacionais. De acordo com suas palavras,

[...] estou também convencido que os trustes estrangeiros de petróleo querem manter-nos em escravização petrolífera, e em consequência agem cá de mil maneiras para acampar as boas estruturas com o fim de pô-las fora do alcance da exploração. Desconfio, pois, sistematicamente de todas as entidades estrangeiras que se 
metem em petróleo no Brasil, já que a intenção confessada não é tirá-lo, sim impedir que o tiremos. Acho, entretanto, que do ponto de vista comercial estas entidades estrangeiras estão certas. Estão agindo como bons e sábios negociantes, dos que enxergam longe e preveem o futuro. Quem não está agindo com inteligência somos nós, fechando os olhos a isso, duvidando disso, permitindo que isso se vá fazendo indefinitivamente. Não os denuncio e combato por serem estrangeiros, mas apenas por estarem seguindo uma política contrária aos nossos interesses. (Monteiro Lobato, s. d., p. 128)

Por outro lado, cabe destacar que a crítica de Lobato visava conseguir benefícios do Estado para viabilizar os empreendimentos das companhias privadas das quais era sócio, por meio do compartilhamento de informações e equipamentos (Cohn, 2017). No entanto, a posição oficial era de que havia carência de recursos financeiros e de técnicos brasileiros habilitados.

A esse respeito, é preciso assinalar que a falta de profissionais era, de fato, um obstáculo para o avanço da exploração de petróleo no país e, segundo Peyerl (2017), continuaria a ser um entrave para a indústria petrolífera no Brasil durante muitas décadas, mesmo após a criação da Petrobras. Já sobre a veracidade das acusações de Monteiro Lobato, Cohn (2017) adverte para o fato de que a adoção pelo Ministério da Agricultura e pelo DNPM do parecer de técnicos estrangeiros sobre a inexistência de petróleo em determinadas regiões que mais tarde se comprovariam produtivas pode indicar que havia, efetivamente, atuação de interesses estrangeiros nos órgãos oficiais para impedir avanços no país.

De todo modo, o fato é que Monteiro Lobato, de novo, não foi ouvido. Diante de mais um insucesso, voltou a escrever livros infantis - o que resultaria na publicação de Geografia de Dona Benta (1935), História das invenções (1935) e Memórias de Emília (1936). Não obstante, no início de 1935, enviou relato a Getúlio Vargas, no qual denunciava interesses escusos da Standard Oil, que estaria pretendendo se apoderar das reservas brasileiras por meio de sua subsidiária argentina. E acusava os técnicos estrangeiros contratados pelo DNPM, Mark Malamphy, diretor de Geofisica, eVitor Oppenheim, ${ }^{9}$ diretor de Geologia, de serem agentes da empresa norte-americana infiltrados no Brasil. Lobato não se continha, declarando que as informações geológicas

\footnotetext{
${ }^{9}$ Curiosamente, Vitor Oppenheim havia iniciado a sua carreira no Brasil - após trabalhar na Argentina e no Paraguai - justamente na empresa de Monteiro Lobato e Carvalho, sendo demitido por seus relatórios pessimistas sobre as oportunidades de se encontrar petróleo em Alagoas (Dias; Quaglino, 1993).
} 
eram falsificadas com a colaboração de técnicos brasileiros, como Domingos Fleury da Rocha, com o objetivo de beneficiar empresas estrangeiras. Em contrapartida, funcionários do Ministério da Agricultura consideravam a influência estrangeira no DNPM como natural e de grande contribuição, como declarou o técnico do Governo Federal, Jesus Soares Pereira:

O nosso Serviço Geológico e Mineralógico foi dirigido por um período grande por estrangeiros, principalmente americanos, que se integraram totalmente no país, sendo capazes de ir ao suicídio em virtude dos desencantos e desacertos e das decepções com as coisas brasileiras, como aconteceu com Orville Derby..$^{10}$ Quando lemos qualquer coisa sobre a nossa geologia estamos topando a toda hora com a contribuição deixada por técnicos, cientistas e pesquisadores estrangeiros. (Pereira apud Lima, 1975, p. 62)

Em junho de 1935, a Companhia Editora Nacional lançou o livro de Essad Bey, A luta pelo petróleo, para o qual Lobato escreveu prefácio em que denunciava que a política das grandes petrolíferas internacionais era "não tirar petróleo e não deixar que ninguém o tire" (Monteiro Lobato apud Azevedo; Camargos; Sacchetta, 2000, p. 153).

Nos últimos meses de 1935, Lobato buscou apoio de Armando de Salles Oliveira, governador de São Paulo, para conseguir dar continuidade à perfuração do poço de Araquá, tendo em vista que fora obrigado a suspender as atividades por falta de recursos. Não obteve sucesso. Ao mesmo tempo, a Companhia Petróleo Nacional, que fazia perfurações em Alagoas, sofreu intervenção federal, com a interdição de uma sonda.E embora Osman Loureiro, novo governador do estado e entusiasta das pesquisas sobre petróleo, tenha autorizado a retomada das perfurações, a empresa não tinha mais recursos.

Logo a seguir, foi publicada a obra de Anton Zischka, A guerra secreta do petróleo (1936), que, assim como o livro de Essad Bey, obteve grande sucesso de vendas. Ambos os volumes retratavam a ascensão da indústria petrolífera na década de 1920, alimentando teorias conspiratórias que envolviam executivos de companhias petroleiras, diplomacia das grandes potências e elites corruptas de países produtores de petróleo.

\footnotetext{
${ }^{10}$ Orville Adalbert Derby (1851-1915) foi um geólogo e geógrafo norte-americano, naturalizado brasileiro. Fundou e dirigiu a Comissão Geográfica e Geológica de São Paulo e o Serviço Geológico e Mineralógico do Brasil. Suicidou-se no Rio de Janeiro em novembro de 1915, aparentemente descontente com as mudanças promovidas pelo governo Venceslau Brás (1914-1918) nos órgãos de pesquisa em que atuava.
} 
Diante disso, Monteiro Lobato voltou à carga, enviando carta ao Ministro da Agricultura, Odilon Braga, com acusações contra Malamphy e Oppenheim, que, segundo ele, estariam vendendo seus estudos sobre o subsolo brasileiro a empresas estrangeiras. ${ }^{11} \mathrm{O}$ governo decidiu, então, criar uma comissão de inquérito para apurar os fatos, mas nada ficou demonstrado. Em resposta, o escritor publicou o livro O escândalo do Petróleo, no qual afirmava que a riqueza das descobertas em países vizinhos, especialmente Venezuela e Argentina, evidenciava que a falta de reservas no Brasil era decorrente da incapacidade técnica, científica e financeira do governo (Dias; Quaglino, 1993).

A implantação da ditadura, em novembro de 1937, cerceou sua campanha em defesa da participação de empresas privadas nacionais na exploração petrolífera, o que se acentuou a partir de 1938, quando foi criado o Conselho Nacional do Petróleo (CNP). A nova instituição assumiu e concentrou as responsabilidades relacionadas à indústria petrolífera e, nos anos seguintes, adquiriu autonomia administrativa e financeira. A criação do órgão encontrou resistência no âmbito privado e dentro da própria administração pública, atuando de maneira sigilosa para que as companhias internacionais não interferissem no processo. O nível de confidencialidade assemelhava-se aos cuidados adotados em operações militares. As empresas privadas já estabelecidas - e que dependiam diretamente do governo para autorizações e uso de equipamentos - não resistiram à fiscalização e às novas exigências legais impostas, acabando por desaparecer (Cohn, 2017).

Em face da conjuntura, Lobato voltou-se mais uma vez para a literatura infantil, publicando Histórias de Tia Nastácia (1937), Os serões de Dona Benta (1937), O poço do Visconde (1937), O Minotauro: maravilhosas aventuras dos netos de Dona Benta na Grécia Antiga (1939) e O pica-pau amarelo (1939). Mesmo por meio de seus escritos direcionados ao público infantil, continuava a sonhar com seus projetos de prospecção e exploração de petróleo no Brasil, ao ponto de isso estar presente em suas obras de ficção: "A descoberta de petróleo no sítio de Dona Benta abalou o país inteiro" (Monteiro Lobato, 1960, p. 204), escreveu.

Porém, na verdade, ele não se conformava com a criação do CNP e com a política preconizada por seu presidente, General Júlio Caetano Horta Barbosa. Dessa forma, procurou driblar a censura que o impedia de continuar

\footnotetext{
${ }^{11}$ Sobre o tema, ver: "Porque o Brasil não tem petróleo. Carta aberta ao Ministro da Agricultura”, de Monteiro Lobato (s. d., p. 46-50).
} 
a publicar artigos com denúncias contra o governo, enviando uma carta diretamente a Getúlio Vargas. Nela, acusava o CNP de promover verdadeira perseguição às empresas nacionais de petróleo e de defender secretamente o monopólio estatal no setor. A carta, datada de 5 de maio de 1940, estava escrita em termos extremamente duros e até mesmo insolentes, como se pode ver do trecho a seguir:

Dr. Getúlio: O Petróleo! Nunca o problema teve tanta importância; e se com a maior energia e urgência o senhor não toma a si a solução do caso, arrepender-se-á amargamente um dia, e deixará de assinalar a sua passagem pelo Governo com a realização da Grande Coisa. Eu vivi demais esse assunto. No livro ESCÂNDALO DO PETRÓLEO denunciei à nação o crime que se cometia contra ela - e com a maior dor de coração vejo hoje que o oficialismo persiste nesse crime, e agora armado duma arma que não existia antes: o monstruoso tanque chamado CONSELHO NACIONAL DO PETRÓlEO. Dr. Getúlio, pelo amor de Deus ponha de lado a sua displicência e ouça a voz de Jeremias. ${ }^{12} \mathrm{Me}-$ dite por si mesmo no que está se passando.Tenho a certeza de que se assim o fizer, tudo mudará e o pobre Brasil não será crucificado mais uma vez. (Monteiro Lobato, s. d., p. 90-99)

Pelo que se verifica, na carta, além de se colocar no papel de profeta, Monteiro Lobato chegava a acusar Getúlio de displicente. O presidente encaminhou a carta a Horta Barbosa, que contra-atacou por meio de fiscalização severa das suas empresas, além de contestar seus argumentos pouco sólidos por meio de oficios enviados diretamente ao gabinete da Presidência da República (Cohn, 2017). Em seguida, encaminhou oficio ao Tribunal de Segurança Nacional, pedindo a abertura de inquérito contra o escritor. O resultado foi a prisão preventiva de Lobato, primeiramente em janeiro de 1941. Em seguida, ele foi denunciado com fundamento no artigo $3^{\circ}$ da Lei 431/1938 (Lei de Segurança Nacional) (Brasil, 1938), e preso novamente em março do mesmo ano, sob a acusação de injúria contra o presidente e agentes públicos. Porém, acabou absolvido em primeira instância (Almeida, s. d., p. 11-12).

Embora o governo recorresse, Monteiro Lobato não aguardou o resultado final do processo para voltar à carga. Tanto que, ao sair da prisão, enviou a Horta Barbosa uma caixa de bombons acompanhada de uma carta, na qual

\footnotetext{
${ }^{12}$ Referência ao profeta Jeremias, personagem bíblico do Antigo Testamento, a quem são atribuídos o Livro de Jeremias e o Livro das Lamentações.
} 
ironicamente agradecia ao General por the ter proporcionado aquele tempo para refletir:

É profundamente reconhecido que venho agradecer a V. Excia o grande presente que me fez, por intermédio do augusto Tribunal de Segurança, de uns tantos deliciosos e inesquecíveis dias passados na Casa de Detenção desta cidade. Sempre havia sonhado com uma reclusão desta ordem, durante a qual eu ficasse forçosamente a sós comigo mesmo e pudesse meditar sobre o livro de Walter Pitkin. ${ }^{13}[\ldots]$ Pesarosamente tenho talvez de deixar hoje esta prisão, mas seria o maior dos ingratos se [...] não cumprisse o meu dever, batendo na máquina esta carta de agradecimento. Creia, general, que a minha gratidão vai ser eterna. (Monteiro Lobato, s. d., p. 104)

A seguir, escreveu uma carta a Getúlio Vargas, supostamente para cumprimentá-lo por seu aniversário, em 19 de abril. Mas, em tom de deboche, sugeria a criação de uma empresa de petróleo nos moldes da Companhia Siderúrgica Nacional (CSN), e indicava a possibilidade de aproveitamento do General Horta Barbosa e de membros do CNP como combustíveis para as fornalhas das sondas (Monteiro Lobato, s. d., p. 105). Dessa vez Monteiro Lobato pagaria um alto preço por sua insolência, pois esse ato acabaria por levá-lo à prisão ainda em abril de 1941 e, depois, à sua condenação a seis meses de detenção, pena que posteriormente foi reduzida à metade.

Ao sair da cadeia, e profundamente abalado, entrou em depressão, e quase deixou de escrever, sobrevivendo apenas com traduções. Sua única obra publicada em quase três anos foi $A$ chave do tamanho (1942). A depressão se agravou com a morte de seu filho Edgard. Somente começou a se recuperar quando a Companhia Editora Nacional decidiu lançar uma edição comemorativa dos 20 anos da publicação de Urupês. Diante da homenagem e do sucesso, abandonou as traduções e voltou-se novamente para as obras infantis e para a organização do livro $A$ barca de Gleyre (1944), que reúne a correspondência que, durante décadas, manteve com Godofredo Rangel, seu melhor amigo. Ao mesmo tempo, retornou ao mercado editorial, participando da criação da Editora Brasiliense, juntamente com Caio Prado Jr. e Arthur Neiva. Em prefácio à edição de 1946 de O escândalo do petróleo, assim se manifestaria seu amigo Caio Prado Jr.:

Monteiro Lobato apresenta em alto grau, e o revela neste livro e

\footnotetext{
${ }^{13}$ Referência ao escritor norte-americano Walter Boughton Pitkin (1878-1953), autor de Uma introdução à história da estupidez humana.
} 
na sua vida, um traço psicológico que não é frequente no Brasil: o idealismo do progresso material. Temos idealistas, carradas deles. Somos um país de idealistas e qualquer ideia generosa logo enfileira atrás de si uma corrente de esforçados lidadores. Mas isto quando são ideias que apelam diretamente aos sentimentos, e vêm isentas de qualquer traço de preocupação material. Quando são produto único e exclusivo do coração [...]. Mas não coincidem, não se harmonizam e confundem senão muito raramente nisto que é o "idealismo do progresso material" de um Mauá, ${ }^{14}[\ldots]$ e que vamos encontrar tão acentuadamente em Monteiro Lobato. Idealismo que se nutre do alto pensamento e da visão geral e ampla de um mundo melhor, de homens mais bem alimentados, melhor vestidos e abrigados, mas têm suas raízes solidamente plantadas no terreno das realizações práticas, possíveis e imediatas. Entre nós, idealismo parece incompatível com preocupações materiais e objetivos mercantis. Este traço da psicologia brasileira não é de difícil explicação. [...] No cenário brasileiro, Monteiro Lobato representa uma destas poucas exceções de verdadeiro e ardente idealista do progresso material. A origem de seu pensamento encontra-se na consideração deste povo maltratado e sofredor que é o brasileiro, e para o qual criou o símbolo consagrado e imortal do JECA TATU. Mais tarde, o espetáculo da grandeza norte-americana fez-lhe ver o que podia e devia ser um Brasil libertado de suas duras contingências materiais. E pôs mãos à obra. [...] $\mathrm{O}$ grande valor, para o público brasileiro, da experiência de Monteiro Lobato, está em que ele revelou, além de qualquer dúvida, um dos principais fatores do atraso e da pobreza do Brasil. A ação nefasta do imperialismo em países fracos e dependentes como o nosso não é por certo assunto novo. Mas coube a Monteiro Lobato evidenciá-la pela primeira vez entre nós com uma experiência em larga escala que proporciona conclusões seguras e definitivas. (Prado Jr., 1946, p. 9-10)

Como naquele ano também começaram a surgir as primeiras contestações ao Estado Novo, Monteiro Lobato aderiu à campanha. Suas críticas se voltaram muito mais para a esquerda, e ele passou a defender o socialismo e a glorificar Luis Carlos Prestes, secretário-geral do Partido Comunista Brasileiro (PCB), preso desde 1936. No entanto, sua oposição a Getúlio Vargas era mais forte e, quando o PCB se aliou ao ditador, em 1945, ficou tremendamente desiludido, passando a desacreditar de todos os partidos políticos. $\mathrm{O}$ desencanto se acentuou ainda mais com a vitória do General Eurico Gaspar

\footnotetext{
${ }^{14}$ Referência ao comerciante, industrial e banqueiro Irineu Evangelista de Souza, Barão de Mauá (18131889).
} 
Dutra nas eleições presidenciais de 1945. Em resposta, mudou-se para Buenos Aires, onde fundou a Editora Acteon, que publicou seu livro La nueva Argentina, uma história contemporânea daquele país dirigida ao público infantil.

Em 1947, o PCB foi colocado na ilegalidade e os parlamentares que haviam sido eleitos pela legenda em 1945 passaram a ser ameaçados de cassação. Diante disso, Monteiro Lobato voltou ao Brasil no início de 1948, engajando-se imediatamente na campanha em defesa dos mandatos dos comunistas, que, como se sabe, não surtiu efeito. Lançou também um folheto intitulado Zé Brasil, no qual procurava mostrar a exploração dos camponeses pelos grandes proprietários, e que acabou apreendido. Mas sua luta e sua obra estariam logo terminadas: em abril do mesmo ano, sofreu um acidente vascular cerebral que o levaria à morte em 4 de julho de 1948.

\section{Considerações finais}

A figura e a ação de Monteiro Lobato criaram uma grande e compreensível resistência entre profissionais ligados à exploração de petróleo por suas acusações públicas, fundadas em argumentos frágeis e que mais se assemelhavam a teorias da conspiração. O notável escritor parece que jamais compreendeu a sua falta de conhecimento sobre petróleo, economia e geologia.Apesar de seu empenho como empresário, entrou para a história como um dos mais conhecidos autores da literatura brasileira, o que não apaga a relevância que a sua insistente batalha teve para o debate da questão petrolífera no Brasil, conforme destacado por Mário Victor (1970):

$\mathrm{Na}$ história do petróleo brasileiro, o nome de Monteiro Lobato deve ser pronunciado com respeito, esquecendo-se os seus inúmeros erros, naturais da criatura humana. Jamais se poderá falar de petróleo neste País olvidando o nome deste grande pioneiro, pois a maior parte de sua vida, ele a dedicou no sentido de ver o Brasil como produtor de petróleo. E isso já é o bastante para que seja reverenciado através das gerações vindouras. (Victor, 1970, p. 112-113)

No entanto, sua morte, em 1948, impediu-o de testemunhar os grandes avanços que o Brasil teria nos anos seguintes. De fato, a Campanha do Petróleo, que reuniu amplos setores da sociedade em defesa do monopólio da exploração dos recursos pelo Estado, e mobilizou a população em torno da questão da soberania nacional sobre as riquezas do país, acabaria, como se sabe, por levar à criação da Petrobras, em 1953 (Schwarcz; Starling, 2015). 
Passadas sete décadas, verifica-se que a disputa entre os interesses de companhias petrolíferas internacionais e a defesa da soberania nacional continuam sendo temas extremamente atuais no debate político brasileiro. Apesar de os argumentos suscitados por Monteiro Lobato e a discussão em torno da exploração do pré-sal fazerem parte de contextos históricos distintos, existem indícios de que há, em ambos os casos, a atuação de interesses estrangeiros que buscam se beneficiar com informações privilegiadas para alcançarem alterações na legislação. É o que se pode ver de alguns episódios significativos: 1) o recente caso de espionagem na Petrobras, revelado por Edward Snowden, em 2013 (EUA espionaram..., 2013); 2) os telegramas da Embaixada dos Estados Unidos no Brasil, dentre os quais destaca-se um com o sugestivo título "A indústria do petróleo vai conseguir combater a lei do pré-sal?" (Nos bastidores..., 2013); 3) as profundas mudanças no marco regulatório criado para o pré-sal a partir da desestabilização do governo de Dilma Rousseff, em 2015, e o desmonte das políticas neodesenvolvimentistas articuladas para o setor de petróleo e gás durante o governo de seu sucessor, Michel Temer (2016-2018) (Schutte, 2018).

Dessa forma, a luta intensa de Monteiro Lobato e o debate de que participou podem servir para ilustrar a constante disputa entre interesses externos e nacionais na história do petróleo no Brasil e, talvez, instigar ideias que permitam defender e preservar a soberania brasileira sobre os nossos recursos petrolíferos.

\section{Referências}

ABREU,A.A. de;BELOCH, I.; LATTMAN-WELTMAN, F; LAMARÃO, S. T. de N. (Org.). Dicionário histórico-biográfico brasileiro (pós-1930). Rio de Janeiro: FGV/CPDOC, 2001.

ALMEIDA, P. R. de. Monteiro Lobato e a emergência da política do petróleo no Brasil.Disponível em: https://www.researchgate.net/publication/228462634. Acesso em 5 agosto de 2020.

AMINEH, M. P.; GUANG,Y. Energy and geopolitical economy in China: theory and concepts. In: AMINEH, M. P.; GUANG, Y. (Eds.). Geopolitical economy of energy and environment: China and the European Union. Leiden/ Boston: Brill, p. 11-41, 2017. 
AZEVEDO, C. L.; CAMARGOS, M.; SACCHETTA, V. Monteiro Lobato: furacão na Botocúndia. São Paulo: Senac, 2000.

AZEVEDO,J.S. G. Mudanças no setor de petróleo: novo papel da Petrobras In: MATTOSO, J.; CARNEIRO, R. (Org.) O Brasil de amanhã. São Paulo: Fundação Perseu Abramo, p. 119-147, 2018.

BOSI, A. História concisa da literatura brasileira. São Paulo: Cultrix, 1970.

BRAGA, O. Bases para o inquérito sobre o petróleo: exposição feita ao Senhor Presidente da República em março de 1936. Rio de Janeiro: Diretoria de Estatística da Produção, 1931.

BRASIL. Decreto n ${ }^{\circ}$ 24.642, de 10 de julho de 1934. Decreta o Código de Minas. Diário Oficial da União. Rio de Janeiro, 1934. Disponível em https:// www2.camara.leg.br/legin/fed/decret/1930-1939/decreto-24642-10-ju1ho-1934-526357-publicacaooriginal-79587-pe.html. Acesso em 9 abril de 2020.

BRASIL. Presidência da República. Decreto-lei nº 431, de 18 de maio de 1938. Define crimes contra a personalidade internacional, a estrutura e a segurança do Estado e contra a ordem social. Rio de Janeiro, 1938. Disponível em http://www.planalto.gov.br/ccivil_03/decreto-lei/1937-1946/ del0431.htm. Acesso em 23 outubro de 2020.

COHN, G. Petróleo e nacionalismo. São Paulo: Editora Unifesp, 2017.

DIAS, J. L. M.; QUAGLINO, M. A. A questão do petróleo no Brasil: uma história da Petrobras. Rio de Janeiro: FGV (CPDOC); Petrobras, 1993.

EUA espionaram Petrobras, dizem papeis vazados por Snowden. BBC Brasil, 8 de set. 2013. Disponível em https://www.bbc.com/portuguese/noticias/2013/09/130908_eua_snowden_petrobras_dilma_mm. Acesso em 21 outubro de 2020 .

FURTADO, C. Formação econômica do Brasil. São Paulo: Companhia Editora Nacional, 1969. 
FUSER, I. Energia e Relações Internacionais. São Paulo: Saraiva, 2013.

LIMA, M. Petróleo, energia elétrica, siderurgia: a luta pela emancipação, um depoimento de Jesus Soares Pereira sobre a política de Getúlio Vargas. Rio de Janeiro: Paz e Terra, 1975.

MENDONÇA, M. G.;ABRÃO, R.A. F. O governo Bolsonaro e o petróleo brasileiro. In: CORSI, F. L.; DOS SANTOS, A. Os rumos do Brasil e da América Latina. Bauru: Praxis, p. 97-127, 2020.

MONTEIRO LOBATO, J. B. América. In: MONTEIRO LOBATO, José Bento. Obras completas de Monteiro Lobato, v. 8. São Paulo: Brasiliense, 1951a.

MONTEIRO LOBATO,J.B. A barca de Gleyre. In:MONTEIRO LOBATO, José Bento. Obras completas de Monteiro Lobato, t. 2, v. 12. São Paulo: Brasiliense, 1951b.

MONTEIRO LOBATO, J. B. O escândalo do petróleo e ferro. Onda verde. São Paulo: Brasiliense, s. d.

MONTEIRO LOBATO,J.B. O poço do Visconde. São Paulo: Brasiliense, 1960.

MONTEIRO LOBATO, J. B. Problema vital. In: MONTEIRO LOBATO, José Bento. Obras completas de Monteiro Lobato, v. 8. São Paulo: Brasiliense, 1951c.

MONTEIRO LOBATO, J. B. Velha praga. In: MONTEIRO LOBATO, José Bento. Urupês. Obras completas de Monteiro Lobato, v. 1. São Paulo: Brasiliense, p. 233-240, 1951d.

MORAIS, J. M. Petróleo em águas profundas: uma história tecnológica da Petrobras na exploração e produção offshore. Brasília: Ipea, 2013.

NOS bastidores, o lobby pelo pré-sal. Wikileaks, 13 dez.2013. Disponível em $<$ https://wikileaks.org/Nos-bastidores-o-lobby-pelo-pre.html>.Acesso em 21 outubro de 2020 . 
PEYERL, D. O petróleo no Brasil: exploração, capacitação técnica e ensino de geociências (1864-1968). São Bernardo do Campo: UFABC, 2017.

PRADO Jr., C. Prefácio. In: MONTEIRO LOBATO, José Bento. O escândalo do petróleo e ferro. Onda Verde. São Paulo: Brasiliense, p. 9-10, s. d.

SCHUTTE, G. R.A política neodesenvolvimentista e seu desmonte no caso de Petróleo \& Gás 2003-2017. Textos para discussão (NEEDDS), v. 1, p. 1-67, 2018. Disponível em http://needds.ufabc.edu.br/images/pdf/GIORGIOTDFEV2018.pdf. Acesso em 21 outubro 2020.

SCHUTTE, G. R. Petróleo e gás na era de Bolsonaro e Guedes. In:AZEVEDO, J. S. G.; POCHMANN, M. Brasil: incertezas e submissão? São Paulo: Perseu Abramo, p. 211-230, 2019.

SCHWARCZ, L.; STARLING, H. M. Brasil: uma biografia. São Paulo: Companhia das Letras, 2015.

VICTOR, M. A batalha do petróleo brasileiro. Rio de Janeiro: Civilização Brasileira, 1970.

YERGIN, D. The prize: the epic quest for oil, money and power. NewYork: Simon \& Schuster, 1991. 